\title{
Graphene Encapsulated Al Particles for Improvement of Thermal Conductivity in Composites
}

\author{
Jinuk Hwang ${ }^{1}$, Woo-Seong Tak ${ }^{1}$, So Youn Mun ${ }^{1}$, Sangyong Nam ${ }^{2}$, Sook Young Moon ${ }^{3}$ and \\ Woo Sik Kim 1,*(D) \\ 1 Fibrous Ceramics and Aerospace Materials Center, Korea Institute of Ceramic Science and Technology, \\ Jinju-si 52851, Korea; ghkdwlsdnr11@gmail.com (J.H.); tws1206@kicet.re.kr (W.-S.T.); \\ msy@kicet.re.kr (S.Y.M.) \\ 2 Department of Materials Engineering and Convergence Technology, Engineering Research Institute, \\ Gyeongsang National University, Jinju-si 52851, Korea; walden@gnu.ac.kr \\ 3 Institute of Advanced Composite Materials, Korea Institute of Science and Technology (KIST), \\ 55324 Wanju-gun, Korea; moon.sookyoung@kist.re.kr \\ * Correspondence: wskim@kicet.re.kr
}

Received: 29 June 2020; Accepted: 11 August 2020; Published: 14 August 2020

\begin{abstract}
Graphene reinforced aluminum matrix composites (GRAMCs) with improved thermal conductivity were prepared via a $\mathrm{pH}$-controlled self-assembly process that involved adjusting the concentration of dispersed graphene oxide (GO) solutions. Uniform dispersion was achieved using $\mathrm{GO}$ coating on the aluminum $(\mathrm{Al})$ surfaces. Graphene encapsulated $\mathrm{Al}$ powders $(\mathrm{Al} / \mathrm{GO})$ were sintered through spark plasma sintering (SPS) to prepare bulk composites, these were then analyzed to determine the thermal and mechanical properties. The density of the $\mathrm{Al} / \mathrm{GO}$ composites was determined to be $99 \%$ or more compared to the theoretical density of pure Al. The Vicker's hardness and thermal conductivity increased by about $47 \%$ and $15 \%$ more than the pristine Al bulks. These processes can improve properties of the thermal interface between $\mathrm{GO}$ and $\mathrm{Al}$, enabling uniform coating without a crosslinking agent. An Al/GO composite, fabricated through the $\mathrm{pH}$-controlled self-assembly process, should be useful for various applications requiring to high thermal conductivity.
\end{abstract}

Keywords: graphene reinforced aluminum matrix composites; self-assembly coating; thermal conductivity; uniform dispersion

\section{Introduction}

Portable electronic devices exhibit continuous demand for light weight, miniaturization and high performance. As the performance of electronic devices improves, more thermal energy is generated in the devices. Failure to efficiently remove the generated heat can cause problems such as reduced performance and lifetime, and increased failure rate of electronic devices [1,2].

The theoretical thermal conductivity of aluminum (Al) is about $230 \mathrm{~W} / \mathrm{mK}$, which is $60 \%$ of the theoretical thermal conductivity of copper $(\mathrm{Cu}, 400 \mathrm{~W} / \mathrm{mK})$. However, $\mathrm{Al}$ has a density $\left(2.70 \mathrm{~g} / \mathrm{cm}^{3}\right)$ lower than that of copper, so it is more suitable than other metal materials as a heat dissipation material for small and lightweight electronic devices [3,4].

Nano carbon materials, such as graphite, carbon nanotubes (CNTs) and graphene, have a hexagonal conjugated structure with carbon atoms and therefore extremely good mechanical strength and thermal and electrical properties $[5,6]$. Graphene is a two-dimensional nano carbon material with sp2-bonded carbon atoms it has a theoretical thermal conductivity of $5000 \mathrm{~W} / \mathrm{mK}$ [7], a very large specific surface area, and it can be combined with various functional materials. Therefore, graphene has various advantages in processes involving dispersing and bonding with matrix materials. It is also used as an additive to improve the mechanical, electrical and thermal properties of composite materials [8-10]. 
Much research on graphene reinforced aluminum matrix composites (GRAMCs) has been conducted to improve the low mechanical strength and the thermal and electrical properties of raw Al. The uniform dispersion of fillers and good interfacial interaction between additives and the matrix materials are important factors influencing the enhancement of characteristics by combining with the Al matrix and carbon fillers [11-13].

In order to further improve the properties of the composite material, many studies attempted to achieve homogeneous dispersion of graphene. However, graphene has very large specific surface area, which can be easily agglomerated by van der Waals forces [14]. In addition, due to low interface bonding between graphene and the passivation oxide layer on the aluminum surface, it is difficult to manufacture excellent GRAMCs $[15,16]$.

The traditional ball-milling method has been the most common choice to attempt homogeneous dispersion of graphene. Nevertheless, complete dispersion of nano-sized graphene was not achived. The weak mechanical strength of $\mathrm{Al}$ can lead it to form a plate shape during the ball milling process, which may hinder densification. Lin Jiang et al. [17]. achieved a uniform dispersion by coating oxidized $\mathrm{CNT}$, via surface modification of $\mathrm{Al}$, with poly vinyl alcohol (PVA). Because its coating method led to more homogeneous dispersion than that possible with the ball-milling method, Al/PVA/CNT has been found to have a higher density and tensile strength than those with Al/CNT mixed through. To improve dispersibility, A.F. Boostani et al. [18] synthesized various types of hybrid graphene nano sheets (GNSs) additives through graphene encapsulation, after agglomeration of SiC nanoparticles. These were added to the $\mathrm{Al}$ matrix to prove the effect by calculating the tensile and elongation rates through a mathematical model.

Chuangan et al. [19]. generated electrons from activated metal surfaces under acidic $\mathrm{pH}$ conditions to study the reduction and deposition of graphene oxide (GO). They confirmed that using this mechanism, reduced GO (rGO) was uniformly coated on the surface of individual metal particles. It has been reported that composite particles coated with rGO have high oxidative stability due to excellent bonding between rGO and the metal surfaces. Additionally, acidic solutions allow for the removal and suppression of oxide films present on the metal surface. This can be used eliminate the $\mathrm{Al}_{2} \mathrm{O}_{3}$ layer that causes de-bonding, which can be expected to improve the thermal conductivity of Al-nano carbon composites [20-22].

In this study, GRAMCs with improved dispersibility and thermal conductivity were fabricated by $\mathrm{GO}$ coating on $\mathrm{Al}$ surfaces. The oxide layer on the surface of the $\mathrm{Al}$ particles was removed using the acidity of the GO solution, dispersed in water. Then, GO was coated on Al through a $\mathrm{pH}$-controlled self-assembly reaction between activated $\mathrm{Al}$ powders and dispersed $\mathrm{GO}$ solution. Graphene encapsulated $\mathrm{Al}$ powder $(\mathrm{Al} / \mathrm{GO})$ composites were prepared without $\mathrm{Al}_{4} \mathrm{C}_{3}$ production by using the SPS to perform sintering for a short time at $600{ }^{\circ} \mathrm{C}$. Measurement of the self-assembled GRAMCs was carried out to determine the thermal and mechanical properties according to the variation of $\mathrm{GO}$ contents in the $\mathrm{Al}$ matrix.

\section{Materials and Methods}

\subsection{Synthesis of GRAMCs by GO Coated on Al Surfaces}

Spherical Al particles (99.5\%, Sigma Aldrich, St. Louis, Missouri, USA) with $44 \mu$ m diameter, and commercially produced GO (Grapheneall, Siheung, Korea) were used as raw materials for this experiment. The GO dispersed solution was adjusted to $3.0 \mathrm{pH}$ by adjusting the GO distilled water concentration by carboxyl acid groups of GO. The acidic solution was treated with a tip-ultrasonicator at $300 \mathrm{~W}$ for $1 \mathrm{~h}$ to make a solution with evenly distributed GO. The finished GO solution was transferred to a beaker to be $0.1 \mathrm{wt} . \%-0.6 \mathrm{wt}$.\% based on the weight of $\mathrm{Al}$, and then stirred continuously to prevent the $\mathrm{GO}$ from sinking. Ten $\mathrm{g}$ of aluminum was added to each stirred solution and reacted at a temperature of $60^{\circ} \mathrm{C}$ for $1 \mathrm{~h}$. After completing the reaction for $1 \mathrm{~h}$, it was confirmed that the color of GO solution became completely transparent, from the previous brown color (Figure 1a). After the coating 
process, the $\mathrm{Al} / \mathrm{GO}$ particles were separated from the solution through vacuum filtration to remove the remaining GO in the solution. The powders were then dried over night at $60{ }^{\circ} \mathrm{C}$ in a vacuum oven. One $g$ of the fully-dried Al/GO was inserted into a graphite mold with a diameter of $12.5 \mathrm{~mm}$. Then, sintering was performed for $5 \mathrm{~min}$ while applying a pressure of $50 \mathrm{MPa}$ at a temperature of $600{ }^{\circ} \mathrm{C}$ using SPS (heating rate: $100^{\circ} \mathrm{C} / \mathrm{min}$ ). The sintered samples by SPS were heat treated for $3 \mathrm{~h}$ at $550{ }^{\circ} \mathrm{C}$ in a pressure-less furnace to remove thermal and residual stresses with nitrogen atmosphere.
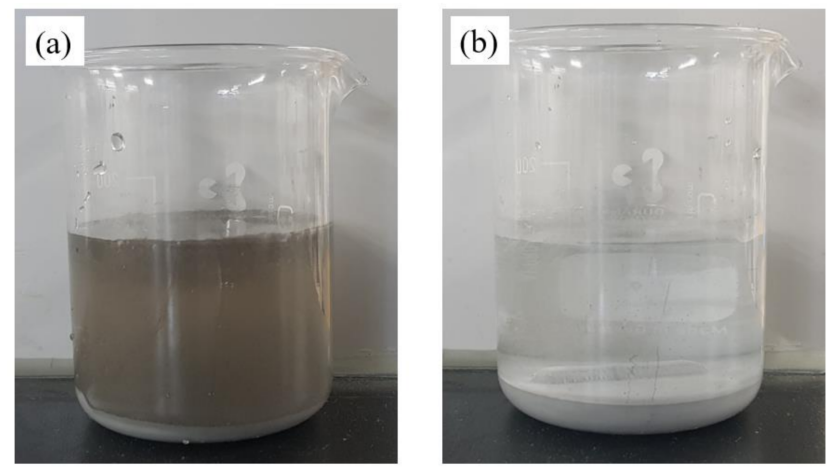

Figure 1. Difference in colors of solution (a) before coating of graphene oxide (GO) on aluminum (Al) particles (brown solution) and (b) after deposition of Graphene encapsulated Al powder (Al/GO) composites particles (clear solution).

\subsection{Characterizations}

The $\mathrm{Al} / \mathrm{GO}$ particles prepared through the self-assembly reaction between $\mathrm{GO}$ solution and $\mathrm{Al}$ powder were analyzed by field emission-scanning electron microscopy (FE-SEM, JSM-6700F, JEOL, Tokyo, Japan) to the determine the microstructure. Raman spectroscopy (inVia Ramanmicroscope $514 \mathrm{~nm}$, Renishaw, Wotton-under-Edge, UK) and X-ray photoelectron spectrometer (XPS, Thermoscientific-Nexsa, Waltham, MA, USA) analyses were performed to confirm the mechanism of reduction and deposition of $\mathrm{GO}$ on the surface-charged $\mathrm{Al}$ particles in acidic solution. The presence or absence of $\mathrm{Al}_{4} \mathrm{C}_{3}$ formation in the sample was confirmed through X-ray diffraction (XRD, D-max 2500, Rigaku, Tokyo, Japan) analysis. Mechanical properties, density and Vicker's hardness (ZHV 30, Zwick Roell, Ulm, Germany) of the samples were measured. The density of bulk composites was measured by using Archimedes principle to calculate the values measured by the hydrometer. Then, thermal properties of $\mathrm{Al} / \mathrm{GO}$, thermal diffusivity and specific heat were analyzed by the laser flash method (LFA-427, NETZSCH, Selb, Germany).

\section{Results}

Microstructures of Al/GO particles having various GO contents prepared through the self-assembly method were compared through FE-SEM analysis. (Figure 2) It was confirmed that GO was uniformly coated on the surface of the Al particles at levels of GO content up to $0.4 \mathrm{wt} \%$ (Figure 2a-d). However, when 0.5 wt.\% of GO or more was used, it was confirmed that GO peeled off the surface of the $\mathrm{Al}$ particles (Figure 2e,f). The exfoliated GO was able to form aggregations inside the sintered composites, and there is a possibility that this reduced the mechanical and thermal properties of the composite material. 

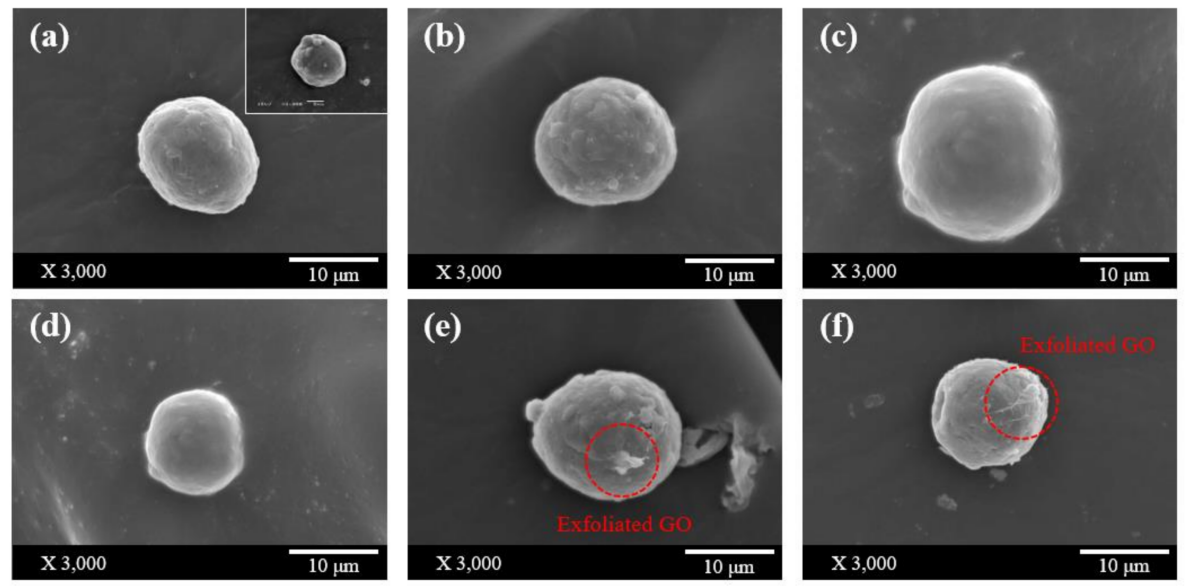

Figure 2. SEM images of (a) $\mathrm{Al} / \mathrm{GO} 0.1 \mathrm{wt}$. $\%$ and pristine $\mathrm{Al}$ particle (inset image), (b-f) $\mathrm{Al} / \mathrm{GO}$ 0.2 wt. $\%-0.6$ wt. $\%$.

To confirm the presence of GO coating on the surface of the $\mathrm{Al}$ particles, Figure 3a shows a comparison of Raman spectra of the pristine $\mathrm{Al}, \mathrm{GO}$ and $\mathrm{Al} / \mathrm{GO} 0.3 \mathrm{wt} \%$. Raman spectra were measured in the range of 1000 to $2000 \mathrm{~cm}^{-1}$. No peak of pristine $\mathrm{Al}$ powder was observed in the range of measurement, but peaks of the $\mathrm{GO}$ and $\mathrm{Al} / \mathrm{GO} 0.3 \mathrm{wt} . \%$ samples were identified and had the same values as that of GO in the $G$ band $\left(1580 \mathrm{~cm}^{-1}\right)$, showing sp $\mathrm{sp}^{2}$ inding, a D band $\left(1350 \mathrm{~cm}^{-1}\right)$ was also generated by $\mathrm{sp}^{3}$ bonding of graphene [23].
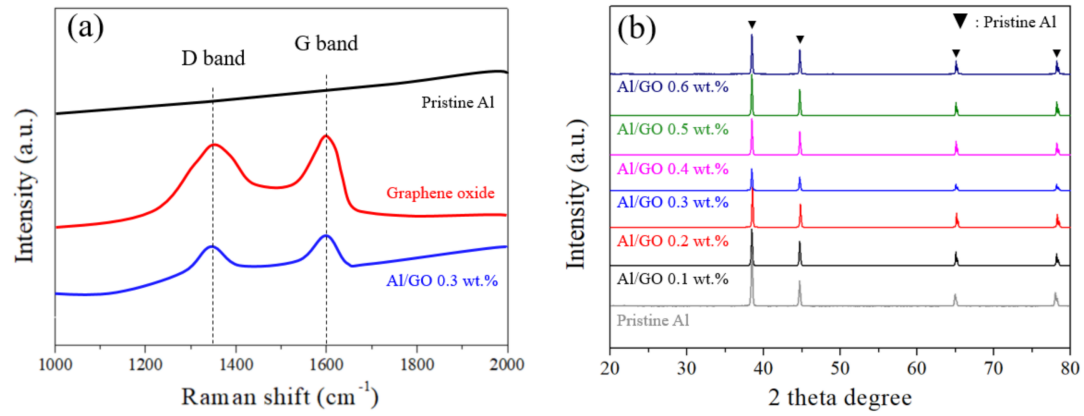

Figure 3. Comparison of (a) Raman spectra of bare $\mathrm{Al}, \mathrm{GO}$ and $\mathrm{Al} / \mathrm{GO}$ 0.3wt.\% powder and (b) XRD patterns of sintered $\mathrm{Al} / \mathrm{GO}$ composites for verity of $\mathrm{GO}$ contents.

The formation of $\mathrm{Al}_{4} \mathrm{C}_{3}$ at the interface of $\mathrm{Al}$ and graphene is known to decrease the mechanical, thermal and electrical properties of GRAMCs. $\mathrm{Al}_{4} \mathrm{C}_{3}$ is a brittle compound that can be produced at the interface of $\mathrm{Al}$ and carbon fillers. Excess $\mathrm{Al}_{4} \mathrm{C}_{3}$ severely weakens the interface bond strength, and the interface is susceptible to corrosion by water. Due to these characteristics, it is possible to decrease the corrosion resistance and properties of the final composites [24]. Densification using SPS was able to prevent synthesis of the $\mathrm{Al}_{4} \mathrm{C}_{3}$ phase by sintering the $\mathrm{Al}$ and carbon materials in a short period of time [25]. Through XRD analysis, it can be seen that the $\mathrm{Al}_{4} \mathrm{C}_{3}$ phase did not form in any of the GRAMCs produced using various amounts of GO content in the Al matrix (Figure 3b) [26].

The binding energy of sp2 C-C $(284 \mathrm{eV})$ and sp3 C-C $(285 \mathrm{eV})$, due to the structure of graphene, can be clearly seen in the C1s peaks of GO (Figure 4a) and Al/GO 0.3 wt.\% (Figure $4 \mathrm{~b}$ ), analyzed by high resolution XPS. In addition, peaks of C-O $(286 \mathrm{eV})$ and O-C-O $(288 \mathrm{eV})$, of the oxygen containing-functional groups of the samples, were confirmed [27,28]. Table 1 shows all of the components of the high-resolution XPS spectrum (Figure 4). The fabrication of Al/GO generates electrons on the $\mathrm{Al}$ surface where the oxide layer is removed by the acidity of the GO solution. GO in solution reacts with the generated electrons from the Al surface and is coated on the Al particles through reduction and deposition. The $\mathrm{C} 1$ s peak of the $\mathrm{GO}$ revealed a ratio of carbon-carbon bondings 
(sp2 C-C and sp3 C-C) to carbon-oxygen bondings ( $-\mathrm{O}, \mathrm{C}=\mathrm{O}$ and $\mathrm{O}-\mathrm{C}=\mathrm{O}$ ) at 38.31:61.69. On the other hand, C1s peak of the Al/GO $0.3 \mathrm{wt}$ \% showed a ratio of 45.23:54.77. Through XPS results, it was proven that $\mathrm{GO}$ was coated on the $\mathrm{Al}$ surface by reduction and deposition between different materials.
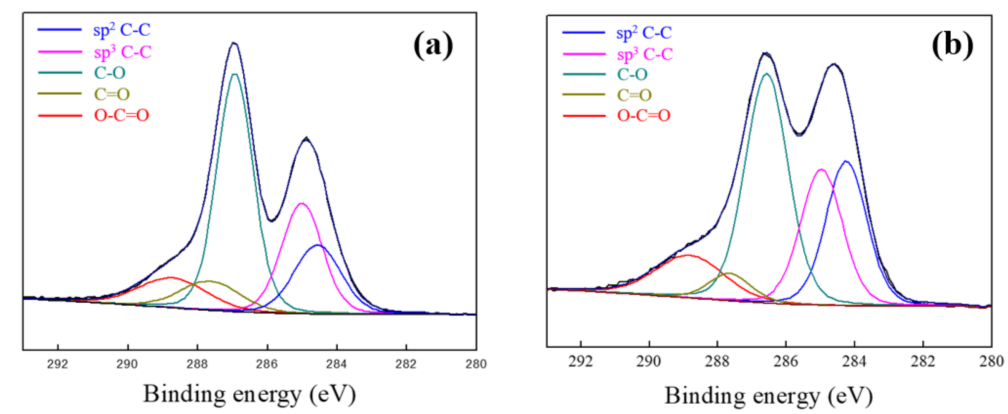

Figure 4. C1s peaks of XPS spectrum: (a) graphene oxide and (b) Al/GO 0.3wt.\%.

Table 1. Curve fitting results of XPS C1s spectra of the GO and the Al/GO 0.3 wt.\%.

\begin{tabular}{cccccc}
\hline GO C1s & Area (\%) & Binding Energy (eV) & Al/GO C1s & Area (\%) & Binding Energy (eV) \\
\hline sp2 C-C & 15.97 & 284.56 & sp2 C-C & 23.03 & 284.25 \\
sp3 C-C & 22.34 & 285.01 & sp3 C-C & 22.20 & 284.97 \\
C-O & 42.82 & 286.93 & C-O & 38.69 & 286.58 \\
C=O & 8.70 & 287.65 & C $=$ O & 4.57 & 287.66 \\
O-C=O & 10.17 & 288.72 & O-C =O & 11.51 & 288.82 \\
\hline
\end{tabular}

Figure 5 shows cross-section SEM images of Al/GO composites prepared by the self-assemble coating and ball-milling method. In Figure 5a, the graphene was well dispersed in the composite material, so aggregated graphene was not observed. In Figure 5b, agglomerated graphene and a number of micro-scale pores were observed (Figure $5 b$ inset). Micro pores of composites degrade the thermal and mechanical properties of GRAMCs. Therefore, graphene must be uniformly dispersed in the $\mathrm{Al}$ matrix in order to improve their properties of $\mathrm{Al} / \mathrm{GO}$ composite. It was confirmed that graphene can be homogeneously distributed in the matrix material through the use of the hybrid materials coated with $\mathrm{GO}$ on $\mathrm{Al}$ particles.
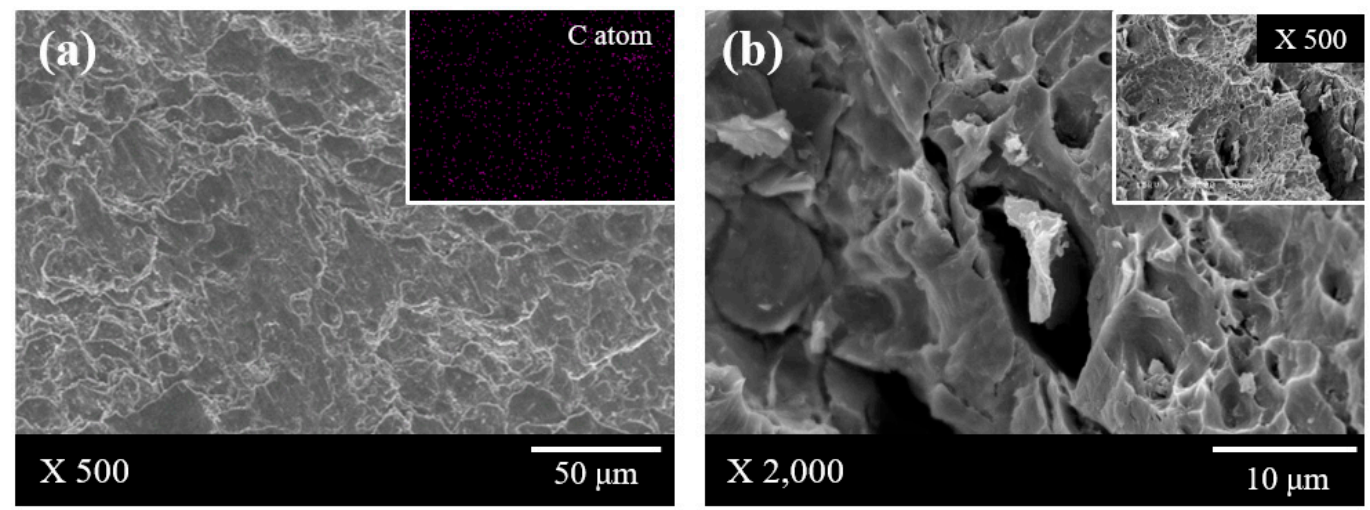

Figure 5. Cross section SEM images of Graphene reinforced aluminum matrix composites (GRAMCs) fabricated by (a) self-assembly coating and (b) ball- milling mixing method.

Table 2. shows the mechanical and thermal properties of all the Al/GO composites prepared through the SPS process. Density of the sintered samples (Figure 6a) decreased with the increase in GO content. It is known that if graphene is not uniformly dispersed in the matrix, density is lowed. However, the density of GRAMCs in this research is close to the theoretical density of pure Al with a relative density of over $99 \%$. If graphene is not uniformly dispersed, they are agglomerated to 
clusters in the Al matrix. The aggregated clusters reduce density through closed pore formation in sintered Al, and finally decease the properties of composites [29,30]. The density of our composites can demonstrate the uniform dispersion of GO in the matrix, higher density by homogeneously dispersed nano-carbon additives.

Table 2. Comparison of the mechanical and thermal properties of all the samples.

\begin{tabular}{|c|c|c|c|c|c|c|}
\hline Samples & $\begin{array}{c}\text { Bulk } \\
\text { Density } \\
\left(\mathrm{g} / \mathrm{cm}^{3}\right)\end{array}$ & $\begin{array}{c}\text { Related } \\
\text { Density } \\
(\%)\end{array}$ & $\begin{array}{c}\text { Vicker's } \\
\text { Hardness } \\
\text { (MPa) }\end{array}$ & $\begin{array}{c}\text { Specific } \\
\text { Heat } \\
(\mathrm{J} / \mathrm{gK})\end{array}$ & $\begin{array}{c}\text { Thermal } \\
\text { Diffusivity } \\
\left(\mathrm{mm}^{2} / \mathrm{s}\right)\end{array}$ & $\begin{array}{c}\text { Thermal } \\
\text { Conductivity } \\
(\mathrm{W} / \mathrm{mK})\end{array}$ \\
\hline Raw Al & 2.699 & 99.93 & 91.83 & 0.899 & 85.27 & 206.9 \\
\hline Al/GO 0.1 wt. $\%$ & 2.694 & 99.78 & 107.67 & 0.907 & 90.18 & 220.4 \\
\hline $\mathrm{Al} / \mathrm{GO} 0.2$ wt. $\%$ & 2.696 & 99.85 & 117.80 & 0.916 & 91.85 & 226.8 \\
\hline Al/GO 0.3 wt. $\%$ & 2.693 & 99.74 & 129.83 & 0.922 & 95.87 & 238.0 \\
\hline Al/GO 0.4 wt. $\%$ & 2.685 & 99.44 & 123.50 & 0.928 & 90.36 & 225.2 \\
\hline Al/GO 0.5 wt. $\%$ & 2.686 & 99.48 & 114.99 & 0.935 & 86.95 & 218.4 \\
\hline Al/GO 0.6 wt. $\%$ & 2.677 & 99.15 & 104.50 & 0.938 & 84.94 & 213.3 \\
\hline
\end{tabular}
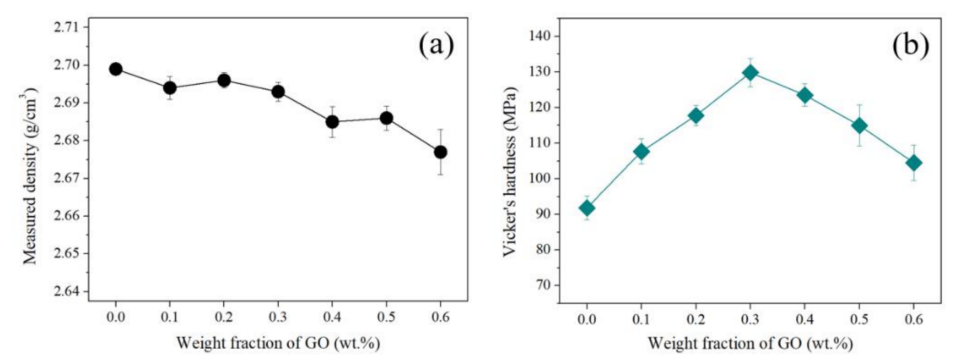

Figure 6. Mechanical properties of composites by weight fraction of GO: (a) density measured using Archimedes principles and (b) Vicker's hardness.

The addition of graphene is known to increase the hardness by providing resistance to deformation when the complex is under pressure. Graphene addition is directly affected by the degree of dispersion of graphene and the interfacial properties of the matrix and additives. In addition, graphene can improve the mechanical properties by generating grain refinement of $\mathrm{Al}$. Therefore, it was confirmed that the GO content increased to $0.3 \mathrm{wt}$ \% and a value of $129.33 \mathrm{MPa}$ was measured for the hardness (Figure 6b). However, when the GO content increased to more than $0.4 \mathrm{wt} \%$, hardness decreased. In Figure $2 \mathrm{f}, \mathrm{g}$, it can be seen that GO was exfoliated from the $\mathrm{Al}$ particles. This problem decreases the density and mechanical properties by forming pores in the composites during the sintering process. Therefore, Al composites uniformly coated with GO can be lighter and harder than pristine Al bulk.

The specific heat and thermal diffusivity were analyzed by the laser flash method at room temperature. Thermal conductivity was calculated using the following equation with the measured $\operatorname{density}(\alpha)$, specific heat $\left(C_{p}\right)$ and thermal diffusivity $(p)$.

$$
\mathrm{k}=\mathrm{a} \times \mathrm{p} \times \mathrm{C}_{\mathrm{p}}
$$

The graph of all calculated thermal conductivity is shown in Figure 7. The result of $\mathrm{Al}$ specimens without addition of $\mathrm{GO}$ was $206.9 \mathrm{~W} / \mathrm{mK}$. However, the $\mathrm{Al} / \mathrm{GO}$ pellet containing $0.3 \mathrm{wt}$ \% of $\mathrm{GO}$ had a thermal conductivity that was about $15 \%$ improved, showing a value of $238.0 \mathrm{~W} / \mathrm{mK}$. 


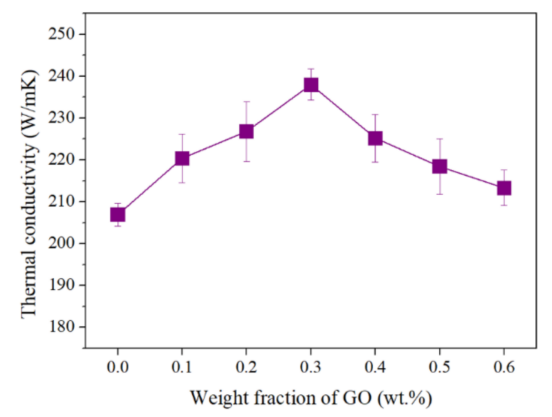

Figure 7. Thermal conductivity of GRAMCs with GO contents of 0 wt. $\%$ to 0.6 wt. $\%$.

\section{Conclusions}

In this work, the characteristics of GRAMCs with thermal conductivity improvements according to GO content were studied. First, $0.1 \mathrm{wt} . \%$ to $0.6 \mathrm{wt} . \%$ of GO coated Al particles were prepared using a $\mathrm{pH}$-controlled self-assembly method to uniformly disperse GO in the Al matrix. Through SEM, XPS and Raman spectroscopy, it was confirmed that the GO was well-coated on the $\mathrm{Al}$ surfaces of the prepared $\mathrm{Al} / \mathrm{GO}$ powders. Then, using SPS to minimize the formation of $\mathrm{Al}_{4} \mathrm{C}_{3}$, sintering was performed for a short period of $5 \mathrm{~min}$ at a temperature of $600^{\circ} \mathrm{C}$. After this, the densified composites were heat treated for $2 \mathrm{~h}$ at a temperature of $550{ }^{\circ} \mathrm{C}$ to improve the thermal conductivity through grain growth. The GRAMCs showed values of Al theoretical density of more than $99 \%$ due to the uniform dispersion of GO in the Al matrix by the self-assembly coating method. In cases of composites having GO content of $0.3 \mathrm{wt} . \%$, the Vicker's hardness increased by $47 \%$ and the thermal conductivity was improved by $15 \%$ compared to those values of bare Al. GRAMCs with GO coating on Al particles are expected to be applicable to high-strength and lightweight heat radiating applications; this mechanism and method can be applied to the development of various metal-nano carbon hybrid materials. We improved the dispersibility of $\mathrm{Al} / \mathrm{GO}$ composites by GO coating on surface of $\mathrm{Al}$ particles. We finished by comparing the characteristics according to the content of GO. In the future, if the layer of GO coated on the $\mathrm{Al}$ powder is controlled as a monolayer, the properties of GRAMCs can be further improved. In addition, the coated GO still has many oxygen functional groups, is thermally decomposed in the sintering process, and maintains the potential to decrease the density of composites by making pores. The generated pores act as a factor to decrease the properties of the composite materials and eliminate the oxygen groups, it is therefore expected to be possible to manufacture GRAMCs with better thermal conductivity.

Author Contributions: Formal analysis, J.H. and S.Y.M. (So Youn Mun); Writing-original draft preparation, J.H.; Writing-review \& editing, S.Y.M. (So Youn Mun) and W.S.K.; Investigation, W.-S.T. and S.Y.M. (Sook Young Moon); Supervision and technical revision, W.S.K. and S.N. All authors have read and agreed to the published version of the manuscript.

Funding: This research received no external funding.

Conflicts of Interest: The authors declare no conflict of interest.

\section{References}

1. Im, H.; Kim, J. Thermal conductivity of a graphene oxide-carbon nanotube hybrid/epoxy composite. Carbon 2012, 50, 5429-5440. [CrossRef]

2. Aravind, S.S.J.; Ramaprabhu, S. Graphene-mutlwalled carbon nanotube-based nanofluides for improved heat dissipation. RCS Adv. 2013, 3, 4199-4206.

3. Miracle, D.B. Metal matrix composites-from science to technological significance. Compos. Sci. Technol. 2005, 65, 2526-2540. [CrossRef]

4. Surappa, M.K. Aluminum matrix composites: Challenges and opportunities. Sadhana 2003, 28, 319-334. [CrossRef] 
5. Suk, J.W.; Piner, R.D.; An, J.; Ruoff, R.S. Mechanical properties of monolayer graphene oxide. Am. Chem. Soc. 2010, 13, 6557-6564. [CrossRef] [PubMed]

6. Ovid'ko, I.A. Mechanical properties of graphene. Rev. Adv. Mater. Sci. 2013, 34, 1-11.

7. Balandin, A.A. Superior thermal conductivity of single-layer graphene. Nano Lett. 2008, 8, 902-907. [CrossRef]

8. Wang, S. Thermal expansion of graphene composites. Macromolecules 2009, 42, 5251-5255. [CrossRef]

9. Goyal, V.; Balandin, A.A. Thermal properties of the hybrid graphene-metal nano-micro-composites: Applications in thermal interface materials. Appl. Phys. Lett. 2012, 100, 073113. [CrossRef]

10. Pérez-Bustamante, R.; Martínez-Sánchez, R. Microstructural and hardness behavior of graphenenanoplatelets/aluminum composites synthesized by mechanical alloying. J. Alloy. Compd. 2014, 615, S578-S582. [CrossRef]

11. Bisht, A.; Srivastava, M.; Lahiri, D. Strengthening mechanism in graphene nanoplatelets reinforced aluminum composite fabricated through spark plasma sintering. Mater. Sci. Eng. A 2017, 695, 20-28. [CrossRef]

12. Guan, R.; Wang, Y.; Zheng, S.; Chen, B. Fabrication of aluminum matrix composites reinforced with Ni-coated graphene nanosheets. Mater. Sci. Eng. A 2019, 754, 437-446. [CrossRef]

13. Ci, L.; Ryu, Z.Y.; Jin-Phillipp, N.Y.; Rühle, M. Investigation of the interfacial reaction between multi-walled carbon nanotubes and aluminum. Acta Mater. 2006, 54, 5367-5375. [CrossRef]

14. Atif, R.; Inam, F. Reasons and remedies for the agglomeration of multilayered graphene and carbon nanotubes in polymers. Beilstein J. Nanotechnol. 2016, 7, 1174-1196. [CrossRef] [PubMed]

15. Bastwros, M.; Zhu, C.; Zhang, K.; Wang, S.; Tang, X.D.; Wang, X.W.; Kim, G.-Y. Effect of ball milling on graphene reinforced Al6061 composite fabricated by semi-solid sintering. Compos. Part B 2014, 60, 111-118. [CrossRef]

16. Lin, C.; Yang, L.L.; Zhi, M. A new method for few-layer graphene preparation via plasma-assisted ball milling. J. Alloy. Compd. 2017, 728, 578-584. [CrossRef]

17. Jiang, L.; Fan, G.; Li, Z.Q. An approach to the uniform dispersion of a high volume fraction of carbon nanotubes in aluminum powder. Carbon 2011, 49, 1965-1971. [CrossRef]

18. Boostani, A.F.; Tahamtanb, S.; Jiang, Z.Y. Enhanced tensile properties of aluminum matrix composites reinforced with graphene encapsulated SiC nanoparticles. Compos. Part A 2015, 68, 155-163. [CrossRef]

19. Hu, C.G.; Zhai, X.Q.; Liu, L.L.; Zhao, Y.; Jiang, L.; Qu, L.T. Spontaneous reduction and assembly of graphene oxide into three-dimensional graphene network on arbitrary conductive substrates. Sci. Rep. 2013, 3, 2065-2074. [CrossRef]

20. Fan, Z.; Wang, K.; Wei, T.; Yan, J.; Song, L.; Shao, B. An environmentally friendly and efficient route for the reduction of graphene oxide by aluminum powder. Carbon 2010, 48, 1670-1692. [CrossRef]

21. Dasari, B.L.; Morshed, M.; Brabazon, J.M.; Saher, S. Mechanical properties of graphene oxide reinforced aluminum matrix composites. Compos. Part B 2018, 145, 136-144. [CrossRef]

22. Li, Z.; Fan, G.; Tan, Z.; Guo, Q.; Xiong, D.; Su, Y.; Zhang, D. Uniform dispersion of graphene oxide in aluminum powder by direct electrostatic absorption for fabrication of graphene/aluminum composites. Nanotechnology 2014, 25, 325601. [CrossRef] [PubMed]

23. Ferrari, A.C.; Meyer, J.C.; Scardaci, V.; Casiraghi, C.; Lazzeri, M.; Mauri, F.; Piscanec, S.; Geim, A.K. Raman spectrum of graphene and graphene layers. Phys. Rev. Lett. 2006, 97, 187401. [CrossRef] [PubMed]

24. Yue, G.; Cai, X.L.; Wang, K.J.; Sun, H.P.; Chen, Y.G. Interface reaction of CNTs/Al composites fabricated by high energy ball milling. Adv. Mater. Res. 2013, 750, 90-94. [CrossRef]

25. Tian, W.; Li, S.; Wang, B.; Chen, X.; Liu, J.; Yu, M. Graphene-reinforced aluminum matrix composites prepared by spark plasma sintering. Int. J. Miner. Met. Mater. 2016, 23, 723-729. [CrossRef]

26. Streletskii, A.N.; Povstugar, I.V.; Borunova, A.B.; Lomaeva, S.F.; Butyagin, P.Y. Mechanochemical activation of aluminum. 4. Kinetics of mechanichemical synthesis of aluminum carbide. Colloid J. 2006, 68, 470-480. [CrossRef]

27. Krishnamoorthy, K.; Veerapandian, M.; Yun, K.; Kim, S.-J. The chemical and structural analysis of graphene oxide with different degrees of oxidation. Carbon 2013, 53, 38-49. [CrossRef]

28. Stobinski, L.; Lesiak, B.; Malolepszy, A.; Mazukiewicz, M.; Mierzwa, B.; Zemek, J.; Jiricek, P.; Bieloshapka, I. Graphene oxide and reduced graphene oxide studied by the XRD, TEM and electron spectroscopy methods. J. Electron Spectrosc. Relat. Phenom. 2014, 195, 145-154. [CrossRef] 
29. Saboori, A.; Moheimani, S.K.; Fino, P. An overview of key challenges in the fabricated of metal matrix composites reinforced by graphene nanoplatelets. Metals 2018, 8, 172. [CrossRef]

30. Saboori, A.; Pavese, M.; Fino, P. Microstructure and thermal conductivity of AL-graphene composites fabricated by powder metallurgy and hot rolling techniques. Acta Metall. Sin. Engl. Lett. 2017, 30, 675-687. [CrossRef] 